\title{
The Bodily Social Self: A Link between Phenomenal and Narrative Selfhood
}

Farmer $\mathrm{H}$. and Tsakiris $\mathrm{M}$.

Published in Review of Psychology and Philosophy, 3:125-144

\section{Abstract}

The Phenomenal Self (PS) is widely considered to be dependent on body representations, whereas the Narrative Self (NS) is generally thought to rely on abstract cognitive representations. The concept of the Bodily Social Self (BSS) might play an important role in explaining how the high level cognitive self-representations enabling the NS might emerge from the bodily basis of the PS. First, the phenomenal self (PS) and narrative self (NS), are briefly examined. Next, the BSS is defined and its potential for explaining aspects of social cognition is explored. The minimal requirements for a BSS are considered, before reviewing empirical evidence regarding the development of the BSS over the first year of life. Finally, evidence on the involvement of the body in social distinctions between self and other is reviewed to illustrate how the BSS is affected by both the bottom up effects of multisensory stimulation and the top down effects of social identification.

\section{Introduction}

The contemporary literature on the self contains a proliferation of differing types of selfhood, indeed Strawson (1999, p. 484) identified no fewer than twenty-one distinct conceptions. In recent years however two of these have come to be considered as 
of particular importance for a complete account of the self (Gallagher, 2000; Zahavi, 2005). On the one hand, the Phenomenal Self (PS) is thought of as a locus of subjectivity and as necessary for all consciousness experience. On the other hand, the Narrative Self (NS), a conceptual form of selfhood, is thought to be the basis for a stable personal identity over time, constituted through the stories that we and others tell about ourselves. What is currently lacking, however, is any detailed account of the relationship between PS and NS. Nonetheless, progress on this issue might be gained by offering a representational analysis of these ideas and examining the potential relationships between them.

\subsection{Phenomenal Selfhood and the Body}

The PS has been closely linked to the body by a number of recent thinkers (Blanke \& Metzinger, 2009; Gallagher, 2003; Legrand, 2006; Zahavi, 2002, 2005m; Hurley, 1998; Bermudéz, 1998; Damasio, 1999). Many draw on the work of phenomenologists such as Merleau-Ponty (1962); others (Bermudéz, 1998, for example) draw on the work of Gibson (1979) to highlight the importance of the body as a source of sensory and motor information (e.g. vision, touch, proprioception) that can be used to differentiate between self and non-self in the absence of a linguistic concept of the self.

Other proponents of the link between the body and the PS stress the role of the body as a point of unification between sensory inputs and motor outputs and thus as the source of a unified and spatially localised first person perspective (1PP). Legrand expresses this role of the body as unifier by saying that: "the self at the bodily level is 
the body itself. It is [...] the body as it is acting and perceiving, that is, the body as the point of convergence of action and perception." (Legrand, 2006, p.108).

A similar point is made by Susan Hurley in her seminal work Consciousness in Action when she states that:

"having a unified perspective involves keeping track of the relationship of interdependence between what is perceived and what is done, and hence awareness of your own agency. In this sense, perspective already involves selfconsciousness. But the sense of self-consciousness that makes good this thought is already tied to ordinary motor agency and spatial perception and need not involve conceptually structured thought or inferences." (Hurley, 1998, p. 141)

If this conception of PS as relying on the integration of different modes of sensorimotor information is correct then it may be possible to better understand the PS by investigating how bodily representations in these different modalities are integrated into a coherent whole. Recent studies have shown that synchronous visuotactile stimulation of a foreign hand and one's own hand can cause the foreign hand to be experienced as part of one's body (Botvinick \& Cohen, 1998; Tsakiris \& Haggard, 2005). Importantly, given the links that some (e.g. Damasio, 1999; Craig, 2003) have made between representations of the internal state of the body and the PS, the altered sense of body-ownership induced by multisensory stimulation is accompanied by changes in the physiologic regulation of the body (Moseley et al., 2008) and is also modulated by awareness of body from within (Tsakiris, TajaduraJiménez, \& Costantini, 2011). Even more suggestive of a link between PS and body 
representation is the finding that similar multisensory stimulation of whole body avatars can induce a shift in the location of one's 1PP implying that the spatial location of the PS is dependent on representations of the location of one's body generated by the integration of multiple modes of sensory information (Lenggenhager, Tadi, Metzinger, \& Blanke, 2007; Petkova et al., 2011).

\subsection{The Narrative Self: A Social Construction}

The NS is an explicit conceptual form of selfhood which emerges through our interactions with others, and in particular through linguistic and cultural identifications of selfhood (Gallagher, 2000). The NS has been elucidated by thinkers from different traditions, with differing conceptions of narrative (e.g. Dennett, 1991; Maclntyre, 1985; Ricoeur, 1988; see Schechtman, 2011 for a review). But all emphasise that the experience of a self as unified and continuous across a lifetime relies upon the ability to situate one's memories, personality traits, goals and values within a coherent narrative structure.

The aspect of the NS which we wish to emphasise is the role played by social interaction in shaping the stories we tell about ourselves. This aspect of the NS was identified by Mead (1913) who argued that having a sense of selfhood involves taking an outside perspective on one's own experience which first develops through thinking about others. The role of other people in the development of the NS is accepted by most proponents of the narrative self. For example Dennett (1991) notes the importance of social practices such as storytelling in allowing children to construct their own narratives later in life and Maclntyre (1985) points out that: "We 
are never more (and sometimes less) than the co-authors of our own narratives. Only in fantasy do we live what story we please" (Maclntyre, 1985, p.213).

In life, in contrast to fictional stories, we can be affected by the goals and desires of others around us. In the earliest periods of our life we are almost totally dependent on the care of others in order to survive and as we grow older we emerge into a social world in which we must define ourselves according to concepts that have specific cultural and historical traditions. In real life we are rarely living out one simple role but instead have multiple and often conflicting memories and beliefs about who we are (Goffman, 1959). The type of narrative that guides one at work is likely to be very different from the narrative one has when with one's partner or friends. So, while at one level the role of the NS is to bring a sense of unity to our lives, it is also important to recognise that this greater narrative is made up of a variety of different sub-narratives that are shaped by different social situations.

This theme of the self as composed of different social narratives is mirrored in two approaches to the self in social psychology; social role theory and the idea of the self-concept. Social role theory argues that our behaviour and attitudes regarding ourselves develop through the social roles we take up. A social role is a comprehensive pattern of behaviour and attitudes that constitute a strategy for coping with a recurrent set of situations (Turner, 1990). These social roles are hypothesised to emerge from an interaction between the individual in the role, the other people they interact with while in that role and the social norms that govern that role (Plummer, 1991). In this way the self is both defined by and plays a part in defining the social roles ascribed to it. The self-concept approach on the other hand 
emphasises the self as a distributed and dynamic representation containing a set of schemata, prototypes, goals and images which can be differentially activated according to the social situation that a person is in (Markus \& Wurf, 1987; Shrauger \& Schoeneman, 1979). Due to their shared emphasis on the importance of structured narratives and social interaction in shaping the sense of self, the social role theory and self-concept theory offer two possible empirical explanations of how we come to acquire a fully developed sense of NS.

\subsection{The Gap between Phenomenal and Narrative Selfhood}

How does the bodily coupling of sensory and motor information that specifies the PS relate to the development of the more sophisticated NS, with its sense of being a self with a narrative history, intertwined with others around it? This issue has received little attention so far, in part due to the different methodologies and traditions that have been involved in defining these two forms of selfhood and their associated forms of self-consciousness. Scientific investigation of bodily self-consciousness has been primarily driven by an emphasis on a solipsistic approach that examines the

role of multisensory input and body representations for the subject, while neglecting the role of interaction with others in the emergence of more complex forms of selfconsciousness (Berlucchi \& Aglioti, 2010; Lenggenhager et al., 2007; Tsakiris \& Frith, 2005). Conversely social psychological approaches to self-consciousness remain largely focused on the concept of the self as a cognitive, often disembodied, process. The self is treated as an abstract symbolic structure, largely separate from both perception and action, and self-consciousness is largely treated as explicit and reflective. As far as there is interest in the body within social psychology it tends to 
focus on the role of society in shaping perceptions of body image (O'Dea \& Abraham, 2000; Rangkakulnuwat, Pothiban, Metzger, \& Tiansawad, 2008;

Strauman, Vookles, Berenstein, Chaiken, \& Higgins, 1991; Strauss, 2000) or in the alteration of the body as a means for self-expression (Sweetman, 1999). For most researchers in the field, the self remains an abstract entity which only happens to be embodied; and indeed, the more general relation between complex forms of selfconsciousness and bodily experience remains a mystery.

\section{The Bodily Social Self}

Having briefly outlined the distinction between the PS and NS and described the disconnection found in their respective literatures we will now introduce a third concept of selfhood; the Bodily Social Self (BSS).

\subsection{What is Bodily Social Selfhood}

In its simplest formulation the Bodily Social Self (BSS) is the first form of selfhood where the self is represented as an object in the world, exposed to the perceptions' of others. As such this form of selfhood also requires the representation of others as having their own perspective separate from that of the self. This is the beginning of what Rochat (2009, p.20) has termed "self-objectification". Importantly the BSS, like the PS, is hypothesised to depend on a bodily form of self-consciousness. By this we mean to say that the BSS is based on the recognition that one's own body can be the object of other's perceptions and thus that the bodies of others are, like one's own, the bearers of a first person perspective (1PP). The sense of representation 
used here need not be taken to require a full blown conceptual representation of other's mental states. Representing others as capable of perceiving one's own body might only require very minimal representation, where the relevant understanding is expressed implicitly through behaviour (e.g. through attracting others attention with loud squeals or giving coy smiles at onset of attention from familiar others) rather than involving explicit knowledge of the other's representation of the self.

A thorough consideration of the BSS is timely given the increased focus on the body in recent social cognition research. This interest has been motivated by an acceptance throughout the cognitive sciences of the important contribution that bodily links between perception and action make to cognition (see Barsalou, 2010). Of particular relevance for the role of the body in social cognition has been the discovery of "mirror systems" in motor, somatosensory and affective areas of the brain which are vicariously activated for both self and other (for recent reviews see: Gallese \& Sinigaglia, 2010; Keysers \& Gazzola, 2009; Rizzolatti \& Fabbri-Destro, 2010). These mirror systems offer the promise of a neurofunctional account of how the behaviour, sensations and emotions of others, observed from a third person perspective (3PP), can be represented in the same way as one's own actions, sensations and emotions, felt from a $1 \mathrm{PP}$, thus explaining a number of social abilities including imitation, empathy and mind reading (Gallese, 2009; Hurley, 2008; Oberman \& Ramachandran, 2007). These developments in social cognitive neuroscience have co-occurred with the development of new approaches to social cognition which challenge the view that social cognition requires the ability to attribute mental states to the behaviour of others (Fuchs \& de Jaegher, 2009; Gallagher \& Hutto, 2008; de Jaegher \& di Paolo, 2007). 
Where does the BSS fit into these new developments in social cognition? We believe that a detailed consideration of the BSS can shed light on both the relationship between shared representations such as the ones driven by the mirror system and the bodily PS, and the issue of how social interactions both contribute to and develop out of the sense of BSS possessed by the interacting agents.

Concerning shared representations between self and other, one issue in which the concept of the BSS can play an illuminating role is the question of exactly which level of self-representation is required for the ability to match the action of one's self and others. Since mirror systems are generally thought of as matching one's 3PP of others' bodies to one's 1PP of one's own body (Gallese, 2009) it seems reasonable to assume that, in order for this to be possible, it is first necessary to be able to take a 3PP towards one's own body. For if a subject does not have the ability to represent, albeit implicitly, their body from a 3PP (i.e. in allocentric terms) it is unclear how they could map the body of another, which is always seen from an allocentric perspective onto their own. Little consideration has been given thus far to the question of how far this ability to take a 3PP on one's self is linked to the capacity to see others as having a similar 3PP towards one's self.

The BSS also provides a useful new perspective on the issue of bodily interactions. One key question is how early social interactions with caregivers are involved in the development of the BSS and, reciprocally, how the emergence of the BSS opens up new forms of interaction with others and paves the way for the development of the more fully-fleshed sense of social selfhood seen in the NS. Another key question 
related to this is how higher levels of self-identification affect embodied social interactions?

\subsection{Conditions for Bodily Social Selfhood}

What are the requirements for possessing a BSS? To answer this question we must consider the abilities an agent must possess in order to represent itself as perceivable by others. In our view the necessary conditions for a BSS boil down to two key points: 1) the possession of a phenomenally self-conscious 1PP and 2) the ability to represent that there are other subjects in the world who are capable of representing the agent as an object in the world. The first of these requirements is relatively self-explanatory, in order for an agent to identify itself as an object for others (seen from a 3PP) it is necessary that it also possess a 1PP representation of itself against which this can be mapped. Without a first person representation of the self, there would be nothing to distinguish the representation of one's self from a 3PP from another object in the world.

The second requirement for the BSS is more difficult to pin down. As stated above an agent need not have a complete conceptual representation of others' mental states in order to possess a minimal representation of its body as the object of another's perception. The possession of such a minimal representation may nonetheless be inferred from the agent's actions in attracting and responding to the intentions of others. In any case, the key question in determining the requirement for meeting this second condition for BSS is this: At what level of social interaction does awareness of one's self as being an object of other's attention emerge? In order to 
determine this it is necessary to examine different types of social interaction in a little more detail.

Knoblich \& Sebanz (2008) provide a useful analysis of four different scenarios of social interaction that an agent could be involved in. Each of these involves a different level of complexity in the underlying mechanisms. At the simplest level is the ability for two systems to become synchronised with either each other or an object in the environment. The second level requires the agent to be able to map the actions, sensations and emotions of the other onto its own sensorimotor and affective systems, and thus to understand other's actions and sensations through its own body. At the third level the agent has the capacity to jointly attend to a stimulus with another person while retaining a separation between its own perceptions and those of the other. At the final level the agent is capable of engaging in joint action with the other while still maintaining separate representations of their own intentions and those of the other.

At which of these levels of social interaction is it necessary to possess a BSS? The key question here is at what level it first becomes necessary to perceive the other as being able to perceive oneself. Since entrainment is a phenomenon that occurs across a wide range of physical and biological systems (Clayton, Sager, \& Will, 2005) it is clear that simply becoming entrained to the actions of another does not require the ability to represent others or even the possession of a PS. As we state above, it is arguable that the second level of social interaction, i.e., the ability to map others onto one's own sensorimotor systems, requires the ability to take a 3PP on one's own body. It is also likely that this mapping plays a role in enabling more 
complex levels of social interaction, which may then feedback to modulate this sensorimotor mapping. However, because at this level, at least in its simplest form, there is no need for self and other representations to be distinguished, it seems that this ability is necessary but not sufficient for the existence of the BSS. Crucially the third level, the ability for joint attention, is the first at which it is necessary not only to represent the other person's action and perception but also to keep these representations separate from those of one's own (Tomasello, Carpenter, Call, Behne, \& Moll, 2005). Thus the ability to jointly attend with others is the first level of social interaction which requires the possession of a BSS and thus the first level at which we can be confident that a rudimentary form of the BSS has developed. Having given these criteria for possession of a minimal form of BSS we will now consider how this sense of BSS develops from early social interactions with others.

\section{The Development of Bodily Social Selfhood}

\subsection{Social Interaction in the First 2 Months of Life}

There is a now a large amount of evidence that human infants are born with a predisposition towards social stimuli. Neonates are able to discriminate faces from

other stimuli (e.g. Mondloch et al., 1999), to preferentially track moving face stimuli (Johnson, Dziurawiec, Ellis, \& Morton, 1991) and are even able to recognise and discriminate between the faces of different people (e.g. their mother from a stranger) within days of birth (Bushnell, 2001; Field, Cohen, Garcia, \& Greenberg, 1984; Walton, Bower, \& Bower, 1992). Indeed a recent study that used four-dimensional ultrasonography to observe the tactile exploration of twins in the womb suggests that 
the ability to distinguish between other people and the rest of the environment can, in certain circumstances, develop before birth (Castiello et al., 2010).

As well as this evidence for newborns having a perceptual bias towards social stimuli it is also clear that, from birth onwards, infants begin to enter into progressively more complex forms of social interaction. As Kaye (1982) has pointed out the earliest and most basic form of social interaction that the newborn encounters is breast feeding. Several studies (e.g. Lavelli \& Poli, 1998; Thoman, Leiderman, \& Olson, 1972) have shown that breastfeeding involves a cycle of mutual adjustment between infant and mother. When infants pause in feeding, mothers instinctively jiggle the infant in order to prompt them to resume feeding. This behaviour is fully interactive as it requires the infant to modulate its own behaviour by postponing sucking during tactile stimulation. In breastfeeding, mother and infant form a coupled system in which both are involved in a mutually regulating interaction (Krueger, 2011). Of particular note is that this early and fully bodily form of social interaction already contains the basic aspects of turn taking and action and response that characterise later more developed interactions with others.

At this point we would like to deal with one possible objection to the account of BSS development which we are putting forward; this is the claim that rather than emerging over the early months of life a sense of social selfhood is already present at birth. This view has been put forward by Meltzoff and colleagues (Gallagher \& Meltzoff, 1996; Meltzoff \& Moore, 1995) based on findings that infants are able to imitate some gestures from birth (e.g. Meltzoff \& Moore, 1983), suggesting the presence of the ability to match their own intentional movements to that of another 
person and therefore have the sense of others as being similarly embodied to the self. There are two reasons however to doubt the veracity of claims relating to neonatal imitation. Firstly, despite being regularly cited as evidence of neonatal possession of a sense of others as intentional, the evidence for neonatal imitation is less convincing than is often assumed. In particular only a very small number of gestures, such as tongue protrusion have been found to be reliably imitated by neonates and these gestures can also be interpreted as generalized, exploratory responses to arousing stimuli, and response competition rather than true imitation (for two recent critiques of neonatal imitation see Jones, 2009; Ray \& Heyes, 2011). Moreover recent research into the development of mirror systems, which are often cited as the neural basis for neonatal imitation (Meltzoff \& Decety, 2003; Rizzolatti, Fogassi, \& Gallese, 2001), suggests that, rather than being present at birth, these systems develop via a combination of Hebbian learning and experiential canalisation (Del Giudice, Manera, \& Keysers, 2009; Heyes, 2010). Secondly, even if the capacity for imitation is innate, the ability to map the actions of others onto one's own actions repertoire itself is not sufficient for the possession of a BSS as it does not require the infant to distinguish between action of self and other and thus the ability to see their self as an object of the other's perception. It only requires the second level of social interaction described by Knoblich \& Sebanz (2008).

If infants do need to be exposed to social interaction to develop a BSS then how does this development progress? Infants' ability to interact with others rapidly moves from the basic sensory dialogue into more complex forms of social interactions in which facial and other bodily gestures become more important. By the age of six weeks, infants display evidence of socially elicited smiling (Spitz, 1965) indicating 
that they are aware of the presence of others. This development is rapidly followed by the emergence of cooing and pre-speech movements (Trevarthen, 1980). This constellation of enhanced changes in social awareness that appear by the age of two months has been referred to as "primary intersubjectivity" (Trevarthen, 1979). Shortly after entering this new period of social development infants also show increased sensitivity to the timing and reactions of adults in face to face interaction as demonstrated in experiments using the still face paradigm (Tronick, Adamson, Wise, \& Brazelton, 1978; Rochat, Querido, \& Striano, 1999) in which, following a period of normal interaction between mother and infant, the mother assumes a still, non-responsive face and ceases to provide tactile and vocal stimulation. The period of non-responsiveness typically leads to a neutral or negative affect in the infant (Ellsworth, Muir and Hains, 1993).

Until the age of 2 months or so infants gradually become more aware of the presence of other social partners and begin to take a more exploratory role in social interactions. It is not clear however that these early interactions require the infant to represent the fact that the carer has a perspective separate from that of the infant's. At this stage the infant's role in social interactions is still largely passive, while they show some awareness of other people as distinct from the rest of the environment, the dynamic of the interaction between carer and infant is still largely driven by the carer's attempts to attract infant responses. These responses, which appear to primarily serve as regulators of the attentions and feelings of the carer, do not themselves seem to require any representation as such and can be more parsimoniously explained as basic physiological responses that become entrained to the actions of the infant's carer. The representation of one's self as an object to 
other's that characterises the BSS seems only to become necessary in order to explain the more complex interactions that develop following the second month of life.

\subsection{Attaining a BSS: Joint Attention towards Self and Objects}

Above we identified joint attention as the first stage of social interaction at which it is necessary for infants to possess a BSS. An interesting issue is the order of development between the BSS and joint attention. Do infants first learn to share objects in the world with others and then gain the implicit knowledge that they too can be an object of others attention or do they first learn to apprehend themselves as the focus of adults attention and only then transfer this knowledge to non-self objects in the environment?

There are two possible responses to this question in the literature. The first, more traditional view is that joint attention emerges only towards the end of the first year of life. It is at this point that infants begin to follow the gaze of social partner to see what they are looking at, demonstrating implicit awareness that the adult has their own perspective on the world (Corkum \& Moore, 1998; Nagai \& Asada, 2003). This is also the point at which infants begin to share attention with their social partner, alternating between acting on and attending to an object in the world and following the gaze of their partner to ensure that their partner is also observing the object (Fasel et al., 2002). Thus the ability to maintain joint attention to an external object which occurs at around 9 months is often considered to be the first stage at which infants demonstrate unequivocally that they have an implicit awareness of others as 
possessing, not just a body, but also a perspective separate from that of the infant. On this view then joint attention is seen as a necessary precursor to representing one's own body as perceivable from a 3PP by others (Tomasello et al., 2005).

The alternative position, that infants first come to perceive themselves as an object of others' perceptions and then subsequently develop the ability to attend to objects with others, has been advocated by Reddy (2003), who argues that the emotional reactions of infants to observation by adults develop in ways suggesting increasing self-consciousness from the age of 2 months onwards. These affective responses to the attention of others include reacting to others with "coy" smiles and body movements, showing indifference to the other through avoidance of gaze, making vocalisations in order to attract adult attention and beginning to play "games" of looking towards and away from their social partners. Infants' reactions to the stillface paradigm also suggest some form of awareness that they are the focus of adults' attention.

Additional support for Reddy's theory comes from a study by Striano and Rochat (1999) which found that infants who reacted most strongly to a still face paradigm at the age of 7 months later showed the most engagement in joint attention at 9 months. This effect was independent of either sociability or general maturation, suggesting a direct link between being aware of the other's attention during face to face interactions and being able to jointly attend with others. In addition, at the age of six months, several months before the beginnings of joint attention, infants begin to show purposeful imitation of other's actions (Masur, 2006) and start to show a reasonable accuracy in mapping the topography of the imitated actions on to their 
own body which requires the ability to transform the body of the other, mapped in allocentric space into the egocentric representation that one has of one's own body. Another reason for viewing the awareness of the other's perspective on the self as preceding shared attention to objects is given by Rochat (2009), who suggests that the key drive behind the development of the sharing of attention is the conflict between the infant's development of increased mobility and freedom to explore the environment autonomously and the feelings of attachment towards the caregiver. If this is the case, then it follows that infants would have to develop the understanding that the other is able to attend to them before joint attention can function as useful means of resolving this dilemma between independence and attachment.

These considerations suggest that a form of shared attention focused on the infant's own body may well be present for some time before the development of shared attention to objects. Indeed given that for most of the first year of life interaction between self and others is largely face to face (Lavelli \& Fogel, 2005) it seems likely that the development of joint attention first involves the realisation that the self is the object of other's attention. It is probable then that, although the BSS does depend on the ability to enter into joint attention with others, the first object to which this joint attention is directed to is the infant's own body. However, more detailed empirical research into the developmental trajectories of joint attention and infant selfawareness is needed to fully resolve this issue.

In this section we have laid out two possible developmental trajectories for the BSS over the first year of life concluding that an implicit sense of the BSS emerges, as a precursor to joint attention, in the period following the development of "primary 
intersubjectivity". In the final section we will consider recent evidence suggesting a continued role for the BSS in mature social interactions.

\section{The Body in Mature Social Interaction}

The importance of the NS for mature social interaction does not mean that the BSS or other form of bodily selfhood cease to play a role. Rather, as Rochat (2009) suggests, the different levels of selfhood can be thought of as attractors in an integrated dynamic system, with our level of self-awareness constantly oscillating between them. On this view, once developed the BSS is (like the body itself (James, 1981)) always there, even once more complex conceptual senses of self have emerged.

In this final section we will review evidence from a number of recent studies that demonstrate the involvement of the body in social distinctions between self and other. These studies illustrate both that the bottom-up effects of multisensory stimulation on body representations can influence social judgements and that the top-down effects of social identification can affect the processing of body representations. Finally, we will highlight how the paradigms used to generate these findings may also be modified in order to directly investigate the role of the BSS in mature social cognition. 


\subsection{Interpersonal Multisensory Stimulation: The Enfacement Paradigm}

In the earlier discussion of the PS we saw that the most basic sense of self seems to arise from the integration of sensorimotor information, across both internal (proprioception, interoception, touch, motor), and external (primarily vision but also audition e.g. Zheng, Macdonald, Munhall, \& Johnsrude, 2011) modalities and that multisensory stimulation of a foreign body can alter body representation. A recent series of experiments has examined the results of interpersonal multisensory stimulation between one's own face and that of another (Mazzurega, Pavani, Paladino, \& Schubert, 2011; Paladino, Mazzurega, Pavani, \& Schubert, 2010; Sforza, Bufalari, Haggard, \& Aglioti, 2010; Tsakiris, 2008). In terms of social interaction the face is by far the most important part of the body. Among adults, attending to the other's facial expressions is vital for successful social interaction, as highlighted by the case of people with Moebius syndrome, a congenital condition which causes an inability to form facial expression (Cole, 2009). Moreover facial appearance is often used as a guide to a person's character (Berry \& McArthur, 1986) and people with social phobia avert their attention away from faces (Chen, Ehlers, Clark, \& Mansell, 2002). The importance of the face in social cognition makes multisensory stimulation centred on the face an effective means of experimenting with the bodily basis of social selfhood.

The first example of such an "enfacement" effect is a study by Tsakiris (2008) in which tactile stimulation was delivered to participants while they watched another person receiving tactile stimulation either synchronously or asynchronously. Participants were then asked to judge when a series of composite faces made up of 
the participant's face and that of the person whose face they saw being stroked, i.e., going from $100 \%$ self to $100 \%$ other in $1 \%$ increments or vice versa, contained more of the self or more of the other. It was found that after synchronous, but not asynchronous, stimulation participants showed a bias in recognizing their own face, judging a greater number of the composite faces as containing more self than in prestimulation trials. This indicates that interpersonal multisensory stimulation changes the mental representations of the self's physical appearance and leads to the incorporation of the face of the other into the self-image. Sforza et al. (2010) used a similar paradigm to replicate this effect and also expanded on the findings by demonstrating that the strength of the enfacement effect was positively correlated with participants trait cognitive and emotional empathy and that the effect was stronger with attractive faces than unattractive faces, both of which suggest that the enfacement effect may be modulated by social processing.

Direct evidence of a distinctly social effect of multisensory stimulation for the face was found by Paladino et al. (2010). In this study, rather than judging the categorical perceptual boundary between self and other, participants were asked to rate how close they felt to the (unknown) person in the video. The authors found that, compared to asynchronous visual tactile stimulation, synchronous stimulation caused participants to feel closer to the other person and to view them as more physically similar to themselves. They also projected their own attributes onto the other more and showed greater conformity to the other's judgement about the number of letters on a screen. 
The findings from studies using the enfacement technique demonstrate that bottomup sensory information can play an important role in modulating the physical and social boundaries between self and others. One might think that such effects have little relevance to social interactions in the real world. However, there is a considerable amount of evidence that interpersonal multisensory stimulation has a powerful effect on the way we perceive our self in relation to others, both in interactions between individuals and in the more extreme experience of losing one's sense of self in a crowd.

\subsection{The Importance of Bodily Synchrony in Social Interactions}

The power of synchronous multisensory stimulation to make us feel more similar to the other is the most direct demonstration of a much more pervasive role of bodily synchrony in mature social interaction. The study of human movement has demonstrated that people naturally synchronise their body movements to each other across a variety of different activities including: limb movements (Issartel, Marin, \& Cadopi, 2007; Schmidt, Carello, \& Turvey, 1990), walking (van Ulzen, Lamoth, Daffertshofer, Semin, \& Beek, 2008; Zivotofsky \& Hausdorff, 2007) and the motion of rocking chairs (Richardson, Marsh, Isenhower, Goodman, \& Schmidt, 2007). Such behavioural synchrony has been shown to have an effect on how people perceive social interaction and those they interact with. Miles, Nind, \& Macrae, (2009) asked participants to rate the rapport between two walking figures that could be in a variety of different phases of synchrony and found that participants perceived the rapport between two people walking was strongest when their steps where most synchronised with one another and weakest when they were least synchronised. 
Similarly Hove \& Risen (2009) demonstrated that synchronous movements between partners also lead to greater feelings of affiliation.

The importance of synchrony in social interaction can be most clearly seen in the tendency of people to unconsciously mimic the actions of those around them (for recent reviews see: van Baaren, Janssen, Chartrand, \& Dijksterhuis, 2009;

Chartrand \& van Baaren, 2009). Mimicry has been shown to exert a number of effects on social interaction. For example, being mimicked leads to an increased sense of liking (Chartrand \& Bargh, 1999) and affiliation (Lakin \& Chartrand, 2003) towards the mimicker. This increased liking translates into behavioural consequences as demonstrated by the fact that people give larger tips to waitresses who repeat their exact words (van Baaren, Holland, Steenaert, \& Vanknippenberg, 2003). Mimicry also makes people more pro-social, and partcipants who had been mimicked during an interaction are more likely to help an experimenter pick up a dropped box of pens and to donate money to charity ( van Baaren, Holland, Kawakami, \& Knippenberg, 2004; van Baaren, Horgan, Chartrand, \& Dijkmans, 2004). As well as these socio-cognitive effects mimicry also seems to influence how well people remember others, with people being more likely to remember the details of a social encounter with a person who mimicked them than with one who did not (Macrae, Duffy, Miles, \& Lawrence, 2008).

There is also evidence that people are unconsciously sensitive to the role of mimicry in building social bonds. Lakin \& Chartrand (2003) found that participants who were given the goal to affiliate with others, either consciously or unconsciously through priming, mimicked an experimenter more whan those who did not have the goal to 
affiliate. They also found that when participants failed to affiliate with the other they subsequently increased mimicry. Cheng \& Chartrand (2003) followed up these findings by showing that people with high self monitoring, i.e., a greater awarness of the image they present to others (Snyder, 1974), displayed increased mimicry when interacting with a someone of equal or higher status compared to someone of lower status. This effect was not found in people with low self monitoring suggesting that high self monitors unconsciously recognise the power of mimicry in facilitating social interactions.

The propensity for unconscious mimicry is so widespread that Lakin, Jefferis, Cheng, \& Chartrand (2003) have argued that it must be an evolutionary adaptation which acts to build a sense of affiliation between people like a kind of "social glue." While this theory does offer an explanation for why people so commonly mimic others around them it fails to address the issue of why mimicry leads to increased feelings of closeness in the first place. We believe that the results of the enfacement paradigm suggest one possible answer to this question. When one's own actions are mimicked by a social partner it creates a form of multisensory stimulation in which one's own action intentions are reflected in the actual bodily movements of the mimicker. This synchrony between one's own actions and those of the other would lead to a blurring of the boundary between self and other, creating the feeling of affiliation and closeness observed in the studies detailed above.

Additional support for this idea can be found by considering the role of synchronous bodily movement in many social situations that encourage affiliation within a group. Dancing represents perhaps the most universal example of interpersonal 
synchronisation. From the campfires of traditional hunter gather societies to the "raves" of the industrialised world, people from all cultures gather to dance and feel a sense of bonding and togetherness while doing so. A number of authors (e.g. Brown, 2000; Levitin, 2008) have argued that the human propensity for dance and music has emerged as the result of an adaptation to facilitate group bonding and the sense of community. However there are many other examples; crowds at sporting events, religious gatherings and political rallies will often chant, sing and move in synchrony, Japanese coroporations have long used communal exercise such as Tai Chi as a way to encourage a sense of team work among their emploees and soldiers are trained to march in step in order to develop the feeling of being part of a well-oiled machine. At the most extreme level such group activities can lead to a loss of one's sense of self as a distinct individual and the feeling of being absorbed into a larger group identity a phenomenon known as deindividuation (Mann, Newton, \& Innes, 1982; Mullen, Migdal, \& Rozell, 2003; Zimbardo, 1969). Thus, by blurring the bodily representation of self and other, the interpersonal synchrony of bodies plays a pervasive role in the creation of social bonds and the identification of the self with others.

\subsection{The Effects of Social Identities on Bodily Representations of Self and Other}

In the previous section we examined how low level bodily processes involved in the generation of the NS play a role in the perception of social selfhood. These interactions are however not solely unidirectional. There is considerable evidence that top down social judgements of similarity to one's self, which are, presumably, 
generated at the level of the NS can modulate bodily forms of social interaction and representation.

One group of findings supporting this bidirectional interaction come from studies examining shared body representations. In two experiments (Serino, Giovagnoli, \& Làdavas, 2009; Serino, Pizzoferrato, \& Làdavas, 2008) Serino and colleagues investigated the role of similarity to the self in the phenomenon of visual remapping of touch (VRT) in which observation of another person being touched leads to more accurate detection of touch on one's own body. Serino et al. (2008) gave participants near threshold tactical-stimulation while they viewed images of either their own face, the face of another or an object being touched. It was found that participants' judgements of whether they were being touched were most accurate when observing their own face and least accurate when observing a non-face object. The second study (Serino et al., 2009) demonstrated that, in addition to being modulated by physical distinctions between self and other, VRT is also modulated by participants' in-group identifications. Participants were more accurate in detecting touch when they observed fingers touching a face from the same ethnic or political group as themselves. The second of these findings is especially interesting as it involves a purely social distinction between self and other with no greater bodily similarity between a person with the same views as one's self and one with opposing views.

In-group out-group effects have also been observed in studies investigating sensorimotor empathy for pain. Xu, Zuo, Wang, \& Han (2009) found that the observation of members of a racial out-group receiving painful stimuli led to less BOLD activation in brain areas involved in pain processing than did the observation 
of a racial in-group. Avenanti, Sirigu, \& Aglioti (2010) used transcranial magnetic stimulation (TMS) to observe corticospinal excitability in black and white participants observing a hand of either their own skin colour or a different skin colour being stabbed with a syringe and found that, while observation of an in-group hand being stabbed led to motor suppression, observation of an out-group hand being stabbed resulted in motor excitation! Even more disturbingly this effect was greater for the known out-group than for a hand with a violet skin colour and was correlated with the participants implicit racial bias as measured by an implicit association task (IAT) (Greenwald, McGhee, \& Schwartz, 1998) suggesting that rather than merely being dependent on the physical difference between the in-group and out-group, hands this effect was related to social attitudes.

Social identifications can also affect aspects of dynamic social interaction such as non-conscious mimicry. Yabar, Johnston, Miles, \& Peace, (2006) found greater mimicry of a non-Christian confederate than a Christian confederate among nonChristian participants and that the number of actions of the Christian that participants mimicked was positively correlated to their implicit attitudes towards Christians. In a similar study Bourgeois \& Hess (2008) found greater facial imitation of in-group compared to out-group models. How people construe themselves e.g. whether one's sense of self is independent from or interdependent with one's relationships with others (Markus \& Kitayama, 2010), can also affect mimicry as shown by three studies by van Baaren, Maddux, Chartrand, de Bouter, \& van Knippenberg (2003). In the first two studies participants were primed with either an independent or interdependent self-construal and it was found that those primed with an interdependent self-construal showed greater mimicry than those primed with an 
independent self-construal. In the third study participants from either an independent (American) or interdependent (Japanese) culture were observed while watching a person and the same effect was found. A recent study by Leighton, Bird, Orsini, \& Heyes (2010) demonstrated that the effect of social attitudes on mimicry was direct and beyond participants' control.

\subsection{Future Directions: Investigating the BSS}

Taken together the studies we have reviewed in this section demonstrate the close link between higher-level social cognition and lower-level sensorimotor processing and reveal the importance of the body in social distinctions between self and other. Indeed the experimental paradigms described here suggest that the concept of a BSS might provide a viable way of informing future investigations. For example, one way to investigate the role of BSS would be to examine whether an increase in the saliency of the BSS, e.g. through the observation by others of one's bodily behaviour, would affect social cognition processes and self-other representations. Another possible avenue of research would be to examine differences between those with higher or lower awareness of the body as an object for others and thus presumably a more or less salient BSS, e.g. by examining people's amount of self monitoring (Snyder, 1974) or body objectification (Tiggeman \& Kuring, 2004), in shared body representation paradigms. ${ }^{1}$

As well as their potential for allowing experimental investigation of the BSS, the studies detailed here also raise other interesting questions that have not so far been

\footnotetext{
${ }^{1}$ We are indebted to the Editors for their insightful suggestions on the empirical investigation of the BSS.
} 
addressed. For instance, how do the top-down effects of social views on shared representations of others and the bottom-up effects of interpersonal multisensory stimulation interact? Can interpersonal multisensory stimulation ameliorate the effects of top-down distinctions between self and other by altering the perceived closeness of the other to the self? The questions detailed here and others like them suggest fertile avenues for future research.

\section{Conclusion}

In this paper, we have aimed to show the utility of a novel concept of selfhood, the BSS, in bridging the empirical divide between phenomenal and narrative conceptions of self. We have attempted to define the criteria for the possession of the BSS and examined its development out of early social interactions. We have also reviewed recent findings suggesting that synchrony between our own body and others can shape our sense of closeness between self and others in later life and, conversely, that higher level self-conceptions have effects at the level of bodily representation and actions. The concept of a BSS can play a useful role in the further development of accounts linking the bodily based PS and the social derived NS and may prove a fruitful basis for further empirical study.

\section{References}

Avenanti, A., Sirigu, A., \& Aglioti, Salvatore M. (2010). Racial bias reduces empathic sensorimotor resonance with other-race pain. Current Biology, 20(11), 1018-22. 
Barsalou, L. W. (2010). Grounded Cognition: Past, Present, and Future. Topics in Cognitive Science, 2(4), 716-724.

Berlucchi, G., \& Aglioti, S. M. (2010). The body in the brain revisited. Experimental Brain Research. 200(1), 25-35.

Bermudéz, J. L. (1998). The Paradox of Self-Consciousness. Cambridge, MA, MIT Press.

Berry, D. S., \& McArthur, L. Z. (1986). Perceiving character in faces: the impact of age-related craniofacial changes on social perception. Psychological Bulletin, 100(1), 3-18.

Blanke, O., \& Metzinger, T. (2009). Full-body illusions and minimal phenomenal selfhood. Trends in Cognitive Sciences, 13(1), 7-13.

Botvinick, M., \& Cohen, J. (1998). Rubber hands "feel" touch that eyes see. Nature, 391(6669), 756.

Bourgeois, P., \& Hess, U. (2008). The impact of social context on mimicry. Biological Psychology, 77(3), 343-52.

Brown S. (2000) The "musilanguage" model of music evolution. In The Origins of Music, (Eds) N. L. Wallin, B. Merker, and S. Brown. 271-300. Cambridge: MIT Press.

Bushnell, I. W. R. (2001). Mother's face recognition in newborn infants: learning and memory. Infant and Child Development, 10(1-2), 67-74. 
Castiello, U., Becchio, C., Zoia, S., Nelini, C., Sartori, L., Blason, L., D’Ottavio, G., Bulgheroni, M. \& Gallese, V. (2010). Wired to be social: the ontogeny of human interaction. PloS one, 5(10),

Chartrand, T. L, \& van Baaren, R. B. (2009). Human mimicry. Advances in Experimental Social Psychology, 41, 219-274.

Chartrand, T. L, \& Bargh, J. A. (1999). The chameleon effect: The perceptionbehavior link and social interaction. Journal of Personality and Social Psychology, 76(6), 893-910.

Chen, Y. P., Ehlers, a, Clark, D. M., \& Mansell, W. (2002). Patients with generalized social phobia direct their attention away from faces. Behaviour Research and Therapy, 40(6), 677-87.

Cheng, C. M., \& Chartrand, T. L. (2003). Self-monitoring without awareness: using mimicry as a nonconscious affiliation strategy. Journal of Personality and Social Psychology, 85(6), 1170-9.

Clayton, M., Sager, R., \& Will, U. (2005). In time with the music: the concept of entrainment and its significance for ethnomusicology. European Meetings in Ethnomusicology. 11. 3-142

Cole, J. (2009). Impaired embodiment and intersubjectivity. Phenomenology and the Cognitive Sciences, 8(3), 343-360.

Corkum, V., \& Moore, C. (1998). The origins of joint visual attention in infants. Developmental Psychology, 34(1), 28-38. 
Craig, A. D. (2003). Interoception: the sense of the physiological condition of the body. Current Opinion in Neurobiology, 13(4), 500-505.

Damasio, A. (1999). The Feeling of What Happens: Body and Emotion in the Making of Consciousness, London: Vintage

de Jaegher, H., \& di Paolo, E. (2007). Participatory sense-making an enactive approach to social cognition. Phenomenology and the Cognitive Sciences, 6(4), 485-507.

Del Giudice, M., Manera, V., \& Keysers, C. (2009). Programmed to learn? The ontogeny of mirror neurons. Developmental Science, 12(2), 350-63.

Dennett, D. C. (1991). Consciousness Explained, Boston: Little, Brown

Ellsworth, C. P., Muir, D.W., \& Hains, S. M. J. (1993). Social competence and person-object differentiation: An analysis of the still-face effect. Developmental Psychology, 29, 63-73.

Fasel, I., Deák, G. O., Triesch, J., Movellan, J., Drive, G., \& Jolla, L. (2002). Combining embodied models and empirical research for understanding the development of shared attention: A developmental model of shared attention. Proceedings of the International Conference on Development and Learning, 2. 21-27.

Field, T., Cohen, D, Garcia, R., \& Greenberg, R. (1984). Mother-stranger face discrimination by the newborn. Infant Behavior and Development, 7(1), 19-25. 
Fuchs, T., \& de Jaegher, H. (2009). Enactive intersubjectivity: Participatory sensemaking and mutual incorporation. Phenomenology and the Cognitive Sciences, 8(4), 465-486.

Gallagher, S. (2000). Philosophical conceptions of the self: implications for cognitive science. Trends in Cognitive Sciences, 4(1), 14-21.

Gallagher, S. (2003). Bodily self-awareness and object perception. Theoria et Historia Scientiarum: International Journal for Interdisciplinary Studies, 7(1), 5368.

Gallagher, S. (2008). Direct perception in the intersubjective context. Consciousness and Cognition, 17(2), 535-43.

Gallagher, S., \& Hutto, D. (2008). Understanding others through primary interaction and narrative practice. In J. Zlatev, T. Racine, C. Sinha, \& E. Itkonen (Eds.), The Shared Mind: Perspectives on intersubjectivity (pp. 17-38). Amsterdam: John Benjamins.

Gallagher, S., \& Meltzoff, Andrew N. (1996). The earliest sense of self and others: Merleau-Ponty and recent developmental studies. Philosophical Psychology, 9, 213-236.

Gallese, V. (2009). Mirror Neurons, Embodied Simulation, and the Neural Basis of Social Identification. Psychoanalytic Dialogues, 19(5), 519-536.

Gallese, V., \& Sinigaglia, C. (2010). The bodily self as power for action. Neuropsychologia, 48(3), 746-55. 
Gibson, J.J. (1979). The Ecological Approach to Visual Perception. Boston: Houghton Mifflin.

Goffman, E. (1959). The Presentation of Self in Everyday Life. Garden City, New York: Doubleday Anchor.

Greenwald, A. G., McGhee, D. E., \& Schwartz, J. L. (1998). Measuring individual differences in implicit cognition: the implicit association test. Journal of Personality and Social Psychology, 74(6), 1464-80.

Heyes, C. (2010). Where do mirror neurons come from? Neuroscience and Biobehavioral Reviews, 34(4), 575-83.

Hove, M. J., \& Risen, J. L. (2009). It's all in the timing: Interpersonal synchrony increases affiliation. Social Cognition, 27(6), 949-960.

Hurley, S. L. (1998) Consciousness In Action. Cambridge MA: Harvard University Press.

Hurley, S. L. (2008). The shared circuits model (SCM): how control, mirroring, and simulation can enable imitation, deliberation, and mindreading. The Behavioral and Brain Sciences, 31(1), 1-22.

Issartel, J., Marin, L., \& Cadopi, M. (2007). Unintended interpersonal coordination: "Can we march to the beat of our own drum?". Neuroscience Letters, 411, 174179.

James, W. (1981). The Principles Of Psychology. Cambridge, MA: Harvard University Press. 
Johnson, M. H., Dziurawiec, S., Ellis, H., \& Morton, J. (1991). Newborns' preferential tracking of face-like stimuli and its subsequent decline. Cognition, 40, 1-19.

Jones, S. S. (2009). The development of imitation in infancy. Philosophical Transactions of the Royal Society of London. Series B, Biological Sciences, 364(1528), 2325-35.

Kaye, K. (1982). The Mental and Social Life of Babies: How Parents Create Persons. Chicago: Chicago University Press.

Keysers, C., \& Gazzola, V. (2009). Expanding the mirror: vicarious activity for actions, emotions, and sensations. Current Opinion in Neurobiology, 19(6), 66671.

Knoblich, G., \& Sebanz, N. (2008). Evolving intentions for social interaction: from entrainment to joint action. Philosophical Transactions of the Royal Society of London. Series B, Biological Sciences, 363(1499), 2021-31.

Krueger, J. (2011). Extended cognition and the space of social interaction. Consciousness and Cognition. 20(3), 643-657

Lakin, Jessica L, \& Chartrand, T. L. (2003). Using nonconscious behavioral mimicry to create affiliation and rapport. Psychological Science, 14(4), 334-9.

Lakin, J.L., Jefferis, V. E., Cheng, C.M., \& Chartrand, T.L. (2003). The chameleon effect as social glue: Evidence for the evolutionary significance of nonconscious mimicry. Journal of Nonverbal Behavior, 27(3), 145-162. 
Lavelli, M., \& Fogel, A. (2005). Developmental changes in the relationship between the infant's attention and emotion during early face-to-face communication: the 2-month transition. Developmental Psychology, 41(1), 265-80.

Lavelli, M., \& Poli, M. (1998). Early mother-infant interaction during breast- and bottle-feeding. Infant Behavior and Development, 21(4), 667-683.

Legrand, D. (2006). The Bodily Self: The sensori-motor roots of pre-reflective selfconsciousness. Phenomenology and the Cognitive Sciences, 5(1), 89-118.

Leighton, J., Bird, G., Orsini, C., \& Heyes, C. (2010). Social attitudes modulate automatic imitation. Journal of Experimental Social Psychology, 46(6), 905-910.

Levitin, D. J. (2008). The World in Six Songs: How the Musical Brain Created Human Nature. New York: Penguin Group, Inc.

Lenggenhager, B., Tadi, T., Metzinger, T., \& Blanke, O. (2007). Video ergo sum: manipulating bodily self-consciousness. Science, 317(5841), 1096-9.

Maclntyre, A. (1985). After Virtue, London: Duckworth.

Macrae, C. N., Duffy, O. K., Miles, L. K., \& Lawrence, J. (2008). A case of hand waving: Action synchrony and person perception. Cognition, 109(1), 152-6.

Mann, L., Newton, J. W., \& Innes, J. M. (1982). A test between deindividuation and emergent norm theories of crowd aggression. Journal of Personality and Social Psychology, 42(2), 260-272.

Markus, H. R., \& Kitayama, S. (2010). Cultures and Selves: A Cycle of Mutual Constitution. Perspectives on Psychological Science, 5(4), 420-430. 
Markus, H., \& Wurf, E. (1987). The Dynamic Self-Concept: A Social Psychological Perspective. Annual Review of Psychology, 38(1), 299-337.

Masur, E. F. (2006). Vocal and action imitation by infants and toddlers during dyadic interactions. In S. J. Rogers \& J. H. G. Williams (Eds.), Imitation and the social mind: Autism and typical development. New York: Guildford Press.

Mazzurega, M., Pavani, F., Paladino, M. P., \& Schubert, T. W. (2011). Self-other bodily merging in the context of synchronous but arbitrary-related multisensory inputs. Experimental Brain Research, 213(2-3), 213-221.

Mead, G. H. (1913). The social self. The Journal of Philosophy, Psychology and Scientific Methods, 10(14), 374-380.

Meltzoff, A. N., \& Moore, M. K. (1983). Newborn infants imitate adult facial gestures. Child Development, 54(3), 702-9.

Meltzoff, A.N., \& Moore, K. M. (1995). A theory of the role of imitation in the emergence of self. Advances in Psychology, 112, 73-93.

Meltzoff, A. N, \& Decety, J. (2003). What imitation tells us about social cognition: a rapprochement between developmental psychology and cognitive neuroscience. Philosophical Transactions of the Royal Society of London. Series B, Biological Sciences, 358(1431), 491-500.

Merleau-Ponty, M. (1962). Phenomenology of Perception. London: Routledge. 
Miles, L. K., Nind, L. K., \& Macrae, C. N. (2009). The rhythm of rapport: Interpersonal synchrony and social perception. Journal of Experimental Social Psychology, 45(3), 585-589.

Mondloch, C. J., Lewis, T. L., Budreau, D. R., Maurer, D., Dannemiller, J. L., Stephens, B. R., \& Kleiner-Gathercoal, K. A. (1999). Face perception during early infancy. Psychological Science, 10(5), 419.

Moseley, G. L., Olthof, N., Venema, A., Don, S., Wijers, M., Gallace, A., \& Spence, C. (2008). Psychologically induced cooling of a specific body part caused by the illusory ownership of an artificial counterpart. Proceedings of the National Academy of Sciences of the United States of America, 105(35), 13169-73.

Mullen, B., Migdal, M. J., \& Rozell, D. (2003). Self-awareness, deindividuation, and social identity: unraveling theoretical paradoxes by filling empirical lacunae. Personality \& Social Psychology Bulletin, 29(9), 1071-81.

Nagai, Y., \& Asada, M. (2003). Joint attention emerges through bootstrap learning. Proceedings of the International Conference on Intelligent Robots and Systems, 168-173.

Oberman, L. M., \& Ramachandran, V. S. (2007). The simulating social mind: the role of the mirror neuron system and simulation in the social and communicative deficits of autism spectrum disorders. Psychological Bulletin, 133(2), 310-27.

O'Dea, J. A. \& Abraham, S. (2000). Improving the body image, eating attitudes, and behaviors of young male and female adolescents: a new educational approach 
that focuses on self-esteem. The International Journal of Eating Disorders, 28(1), 43-57.

Paladino, M.-P., Mazzurega, M., Pavani, F., \& Schubert, T. W. (2010). Synchronous multisensory stimulation blurs self-other boundaries. Psychological Science, 21(9), $1202-1207$.

Petkova, V. I., Björnsdotter, M., Gentile, G., Jonsson, T., Li, T.-Q., \& Ehrsson, H. H. (2011). From Part- to Whole-Body Ownership in the Multisensory Brain. Current Biology, doi:10.1016/j.cub.2011.05.022.

Plummer, K. (ed.) (1991). Symbolic Interactionism. 2 vols. Aldershot: Elgar.

Rangkakulnuwat, P., Pothiban, L., Metzger, B. L., \& Tiansawad, S. (2008). Development of the body image self-schema scale and the body image possible selves scale for Thai middle-aged women. Nursing Research, (March), 40-54.

Ray, E., \& Heyes, C. (2011). Imitation in infancy the wealth of the stimuli. Developmental Science, 14(3), 92-105.

Reddy, V. (2003). On being the object of attention: implications for self-other consciousness. Trends in Cognitive Sciences, 7(9), 397-402.

Richardson, M. J., Marsh, K. L., Isenhower, R. W., Goodman, J. R. L., \& Schmidt, R. C. (2007). Rocking together: Dynamics of intentional and unintentional interpersonal coordination. Human Movement Science, 26, 867-891.

Ricoeur, P. (1988) Time and Narrative: Volume 3., trans. Kathleen Blamey and David Pellauer, Chicago: University of Chicago Press 
Rizzolatti, G., \& Fabbri-Destro, M. (2010). Mirror neurons: from discovery to autism. Experimental Brain Research, 200(3-4), 223-37.

Rizzolatti, G., Fogassi, L., \& Gallese, V. (2001). Neurophysiological mechanisms underlying the understanding and imitation of action. Nature Reviews Neuroscience, 2(September), 661-670.

Rochat, P. (2009) Others in Mind - The Social Origin Of Self-Consciousness. New York: Cambridge University Press.

Rochat, P, Querido, J. G., \& Striano, T. (1999). Emerging sensitivity to the timing and structure of protoconversation in early infancy. Developmental Psychology, 35(4), 950-7.

Schechtman, M. (2011) The narrative self. In S. Gallagher (Ed). The Oxford Handbook of The Self. Oxford: OUP

Schmidt, R. C., Carello, C., \& Turvey, M. T. (1990). Phase transitions and critical fluctuations in visual coordination of rhythmic movements between people. Journal of Experimental Psychology: Human Perception and Performance, 16, 227-247.

Serino, A., Giovagnoli, G., \& Làdavas, E. (2009). I feel what you feel if you are similar to me. PloS one, 4(3), e4930.

Serino, A., Pizzoferrato, F., \& Làdavas, E. (2008). Viewing a face (especially one's own face) being touched enhances tactile perception on the face. Psychological Science, 19(5), 434-8. 
Sforza, A., Bufalari, I., Haggard, P., \& Aglioti, S. M. (2010). My face in yours: Visuotactile facial stimulation influences sense of identity. Social Neuroscience, 5(2), 148-62.

Shrauger, J. S. S., \& Schoeneman, T. J. T. J. (1979). Symbolic interactionist view of self-concept: Through the looking glass darkly. Psychological Bulletin, 86(3), $549-573$.

Snyder, M. (1974). Self-monitoring of expressive behavior. Journal of Personality and Social Psychology, 30(4), 526-537.

Spitz, R. (1965). The First Year of Life: A Psychoanalytical Study of Normal and Deviant Development of Object Relations. NY: International Universities.

Strauman, T. J., Vookles, J., Berenstein, V., Chaiken, S., \& Higgins, E. T. (1991). Self-discrepancies and vulnerability to body dissatisfaction and disordered eating. Journal of Personality and Social Psychology, 61(6), 946-56.

Strauss, R. (2000). Childhood obesity and self-esteem. Pediatrics, 105(e15), 1-5.

Strawson, G. (1999)The Self and the SESMET. In S. Gallagher and J. Shear (Eds.), Models of the Self. Thorverton: Imprint Academic.

Striano, T., \& Rochat, P. (1999). Developmental link between dyadic and triadic social competence in infancy. British Journal of Developmental Psychology, 17(4), 551-562. 
Sweetman, P. (2000) Anchoring the (postmodern) self? Body modification, fashion, and identity. In Body Modification. (Ed) M. Featherstone, pp. 51-76. London: Sage Publications.

Thoman, E. B., Leiderman, P. H., \& Olson, J. P. (1972). Neonate-mother interaction during breast-feeding. Developmental Psychology, 6(1), 110-118.

Tiggeman, M. and Kuring, J. K. (2004). The role of body objectification in disordered eating and depressed mood. British Journal of Clinical Psychology, 43, 299-311.

Tomasello, M., Carpenter, M., Call, J., Behne, T., \& Moll, H. (2005). Understanding and sharing intentions: The origins of cultural cognition. Behavioral and Brain Sciences, 28, 675-735.

Trevarthen, C. (1979). Communication and cooperation in early infancy: a description of primary intersubjectivity. In Bullowa, M. (Ed.), Before Speech: The Beginning of Interpersonal Communication. Cambridge University Press, Cambridge, MA,

Trevarthen, C. (1980). The foundation of intersubjectivity: Development of interpersonal and cooperative understanding in infants. In D. R. Olson (Ed.), The social foundation of language and thought. essays in honor of Jerome S. Bruner. New York: W.W. Norton \& Company.

Tronick, E. Z., Als, H., Adamson, L., Wise, S., \& Brazelton, T. B. (1978). The infant's response to entrapment between contradictory messages in face-to-face interaction. Journal of the American Academy of Child Psychiatry, 17, 1-13. 
Tsakiris, M. (2008). Looking for myself: current multisensory input alters self-face recognition. PloS one, 3(12), e4040.

Tsakiris, M., \& Frith, C. D. (2005). Self: neurocognitive approaches. In T Bayne, A Cleeremans \& P Wilken (Eds.). The Oxford Companion to Consciousness. Oxford: Oxford University Press.

Tsakiris, M., \& Haggard, P. (2005). The rubber hand illusion revisited: visuotactile integration and self-attribution. Journal of Experimental Psychology: Human Perception and Performance, 31(1), 80-91.

Tsakiris, M., Tajadura-Jiménez, A., \& Costantini, M. (2011). Just a heartbeat away from one's body: interoceptive sensitivity predicts malleability of bodyrepresentations. Proceedings OF The Royal Society B, 278(1717), 2470-6.

Turner, R. (1990). 'Role change'. Annual Review of Sociology, 16, 87-110.

van Baaren, R. B., Holland, R. W., Kawakami, K., \& Knippenberg, A. V. (2004). Mimicry and Prosocial Behavior. Psychological Science, 15(1), 71-74.

van Baaren, R. B., Holland, R., Steenaert, B., \& Vanknippenberg, A. (2003). Mimicry for money: Behavioral consequences of imitation. Journal of Experimental Social Psychology, 39(4), 393-398.

van Baaren, R. B., Horgan, T. G., Chartrand, T. L., \& Dijkmans, M. (2004). The forest, the trees, and the chameleon: context dependence and mimicry. Journal of Personality and Social Psychology, 86(3), 453-9. 
van Baaren, R. B., Janssen, L., Chartrand, T. L, \& Dijksterhuis, A. (2009). Where is the love? The social aspects of mimicry. Philosophical Transactions of the Royal Society of London. Series B, Biological Sciences, 364(1528), 2381-9.

van Baaren, R. B., Maddux, W. W., Chartrand, T. L., de Bouter, C., \& van Knippenberg, A. (2003). It takes two to mimic: Behavioral consequences of selfconstruals. Journal of Personality and Social Psychology, 84(5), 1093-1102.

van Ulzen, N. R., Lamoth, C. J. C., Daffertshofer, A., Semin, G. R., \& Beek, P. J. (2008). Characteristics of instructed and uninstructed interpersonal coordination while walking side-by-side. Neuroscience Letters, 432, 88-93.

Walton, G. E., Bower, N., \& Bower, T. (1992). Recognition of familiar faces by newborns. Infant Behavior and Development, 15(2), 265-269.

Xu, X., Zuo, X., Wang, X., \& Han, S. (2009). Do you feel my pain? Racial group membership modulates empathic neural responses. The Journal of Neuroscience, 29(26), 8525-9.

Yabar, Y., Johnston, L., Miles, L., \& Peace, V. (2006). Implicit behavioral mimicry: Investigating the impact of group membership. Journal of Nonverbal Behavior, 30(3), 97-113.

Zahavi, D. (2002). First-person thoughts and embodied self-awareness: Some reflections on the relation between recent analytical philosophy and phenomenology. Phenomenology and the Cognitive Sciences, 1, 7-26.

Zahavi, D. (2005). Subjectivity and Selfhood: Investigating the First-Person Perspective. Cambridge, MA: MIT Press/Bradford. 
Zheng, Z. Z., Macdonald, E. N., Munhall, K. G., \& Johnsrude, I. S. (2011). Perceiving a stranger's voice as being one's own: a "rubber voice" illusion? PloS one, 6(4), e18655.

Zimbardo, P. G. (1969). The human choice: Individuation, reason, and order versus deindividuation, impulse, and chaos. Nebraska Symposium on Motivation, 17, 237-307.

Zivotofsky, A. Z., \& Hausdorff, J. M. (2007). The sensory feedback mechanisms enabling couples to walk synchronously: An initial investigation. Journal of Neuroengineering and Rehabilitation, 4, 28. 